\title{
Modifying Building Energy-Saving Design Based on Field Research into Climate Features and Local Residents' Habits
}

\author{
Xiaoyue Zhu ${ }^{1}$, Bo Gao ${ }^{2}$, Xudong Yang ${ }^{3, *}$, Zhong Yu ${ }^{1}$ and Ji Ni ${ }^{1}$ \\ 1 Sichuan Institute of Building Research, Chengdu 610031, China; zhu-xy17@tsinghua.org.cn (X.Z.); \\ 13261767253@163.com (Z.Y.); nijie123123@163.com (J.N.) \\ 2 School of Mechanical Engineering, Southwest Jiaotong University, Chengdu 610031, China; \\ gbswjtu@my.swjtu.edu.cn \\ 3 Department of Building Science, Tsinghua University, Beijing 100084, China \\ * Correspondence: xyang@tsinghua.edu.cn
}

Citation: Zhu, X.; Gao, B.; Yang, X.; $\mathrm{Yu}, \mathrm{Z} . ; \mathrm{Ni}$, J. Modifying Building Energy-Saving Design Based on Field Research into Climate Features and Local Residents' Habits. Energies 2021, 14, 442. https://doi.org/10.3390/ en14020442

Received: 21 December 2020 Accepted: 14 January 2021 Published: 15 January 2021

Publisher's Note: MDPI stays neutral with regard to jurisdictional clai$\mathrm{ms}$ in published maps and institutional affiliations.

Copyright: () 2021 by the authors. Licensee MDPI, Basel, Switzerland. This article is an open access article distributed under the terms and conditions of the Creative Commons Attribution (CC BY) license (https:// creativecommons.org/licenses/by/ $4.0 /)$.

\begin{abstract}
In China, a surging urbanization highlights the significance of building energy conservation. However, most building energy-saving schemes are designed solely in compliance with prescriptive codes and lack consideration of the local situations, resulting in an unsatisfactory effect and a waste of funds. Moreover, the actual effect of the design has yet to be thoroughly verified through field tests. In this study, a method of modifying conventional building energy-saving design based on research into the local climate and residents' living habits was proposed, and residential buildings in Panzhihua, China were selected for trial. Further, the modification scheme was implemented in an actual project with its effect verified by field tests. Research grasps the precise climate features of Panzhihua, which was previously not provided, and concludes that Panzhihua is a hot summer and warm winter zone. Accordingly, the original internal insulation was canceled, and the shading performance of the windows was strengthened instead. Test results suggest that the consequent change of SET ${ }^{*}$ does not exceed $0.5^{\circ} \mathrm{C}$, whereas variations in the energy consumption depend on the room orientation. For rooms receiving less solar radiation, the average energy consumption increased by approximately $20 \%$, whereas for rooms with a severe western exposure, the average energy consumption decreased by approximately $11 \%$. On the other hand, the cost savings of removing the insulation layer are estimated at 177 million RMB $(1 \mathrm{USD} \approx 6.5 \mathrm{RMB})$ per year. In conclusion, the research-based modification method proposed in this study can be an effective tool for improving building energy efficiency adapted to local conditions.
\end{abstract}

Keywords: passive energy-saving design; residential buildings; hot summer and warm winter zone; field test

\section{Introduction}

To cope with climate change and control the global increase in temperature, energy conservation and a reduction of emissions have become global issues. Countries and economies with carbon emission targets account for approximately $75 \%$ of world's gross domestic product (GDP) [1,2]. The building industry, which consumes as much as $45 \%$ of total primary energy worldwide, has been recognized as highly energy-intensive and one of the biggest contributors to global carbon emissions [3-5].

Building energy conservation has been attracting attention from governments and academia. Germany started making efforts toward achieving green buildings during the 1970s and has obtained considerable achievements [6]. The UK government pledged to upgrade the energy efficiency of 7 million residential buildings by 2020 and thereby achieve a $29 \%$ reduction in carbon emissions [7]. The European Union proposed the Energy Performance of Buildings Directive (EPBD), which requires that all new constructions be near zero energy buildings by the end of 2020, and the time limit for existing buildings is 2050 [8]. To achieve the goals set by EPBD, Italy has adopted legislative measures to 
reduce energy consumption of new residential buildings [9]. To encourage a decrease in building emissions and elevating energy efficiency, the United States has launched three major voluntary information programs, namely, the US Environmental Protection Agency's Energy Star Program, the US Green Building Council's Leadership in Energy and Environmental Design, and the US Department of Energy's Better Buildings Challenge [10]. Apart from reducing energy consumption, the "cost-optimal level" is another important performance requirement for buildings. Previous research used Life Cycle Cost analysis (LCC) to determine the "cost-optimal level" with the case study involving a social housing building in Italy [11].

Compared with developed countries, China is facing a more severe challenge in building energy-saving. The building industry has long served as a pillar of China's economy. In 2015, the total output of the building industry alone accounted for $26.4 \%$ of the domestic GDP [12]. However, many new buildings in China fail to meet the energy-saving standards. In addition, a large percentage of the existing buildings consume excessive energy [13].

In fact, building energy-saving efforts in China can trace back to the 1980s, starting from the cold and severe cold regions in the north and gradually promoted to the south. The goal has also evolved from simply saving energy to realizing energy sustainability [14]. During this process, a series of standards had been established [15-19]. As required, an energy-efficient building should comply to the design codes and meet the constraint value of energy consumption index, while achieving satisfactory indoor environment by elevating the energy efficiency. The building thermal design method and relevant database established based on the energy saving demand of buildings in the north have been used thus far. However, it is not necessarily reasonable for southern regions to follow the northern design codes owing to their diverse climatic features. The northern codes mainly focus on reducing the heating load in winter, and thus place special emphasis on the insulation performance of the envelope. However, quite a few studies have revealed that excessive thermal insulation may significantly increase the annual cooling energy consumption for buildings in hot and humid climate zones [20-22]. Moreover, the standards only provide meteorological data collected several decades ago for a small number of representative cities. These data can be obsolete and are still not adequate to refine the division of climate zones in China. As a result, the real climatic characteristics of some areas may differ widely from those suggested by the design standards. Previous studies have noted that it is difficult to optimize the general energy efficiency and ensure the long-term performance of the building through a rigid adherence to prescriptive codes and design norms [23-26]. Therefore, comprehensively improving the building energy efficiency in China requires the design standards to be rooted in the local conditions and quickly upgraded, particularly for the south.

Another deficiency regarding studies on building energy-saving design is that few researchers have presented field measurements from actual cases [27]. The effectiveness of the design is only estimated through simulations. By contrast, few studies have combined energy consumption and thermal comfort index when evaluating the design scheme [28-30].

In this study, a method of modifying conventional building energy-saving design based on research into the local climate and residents' living habits was proposed, and residential buildings in Panzhihua, a city in southwest China, were selected for a trial. The upgraded design scheme is implemented in an actual project and field tests are being conducted to comprehensively evaluate its effects. Both energy consumption and thermal comfort are taken into consideration.

\section{Methods}

Figure 1 shows a flowchart of the modification method to introduce its application process and underlying logic more intuitively. This study followed the procedures shown in the figure, and each step is introduced in detail as below. 
Method

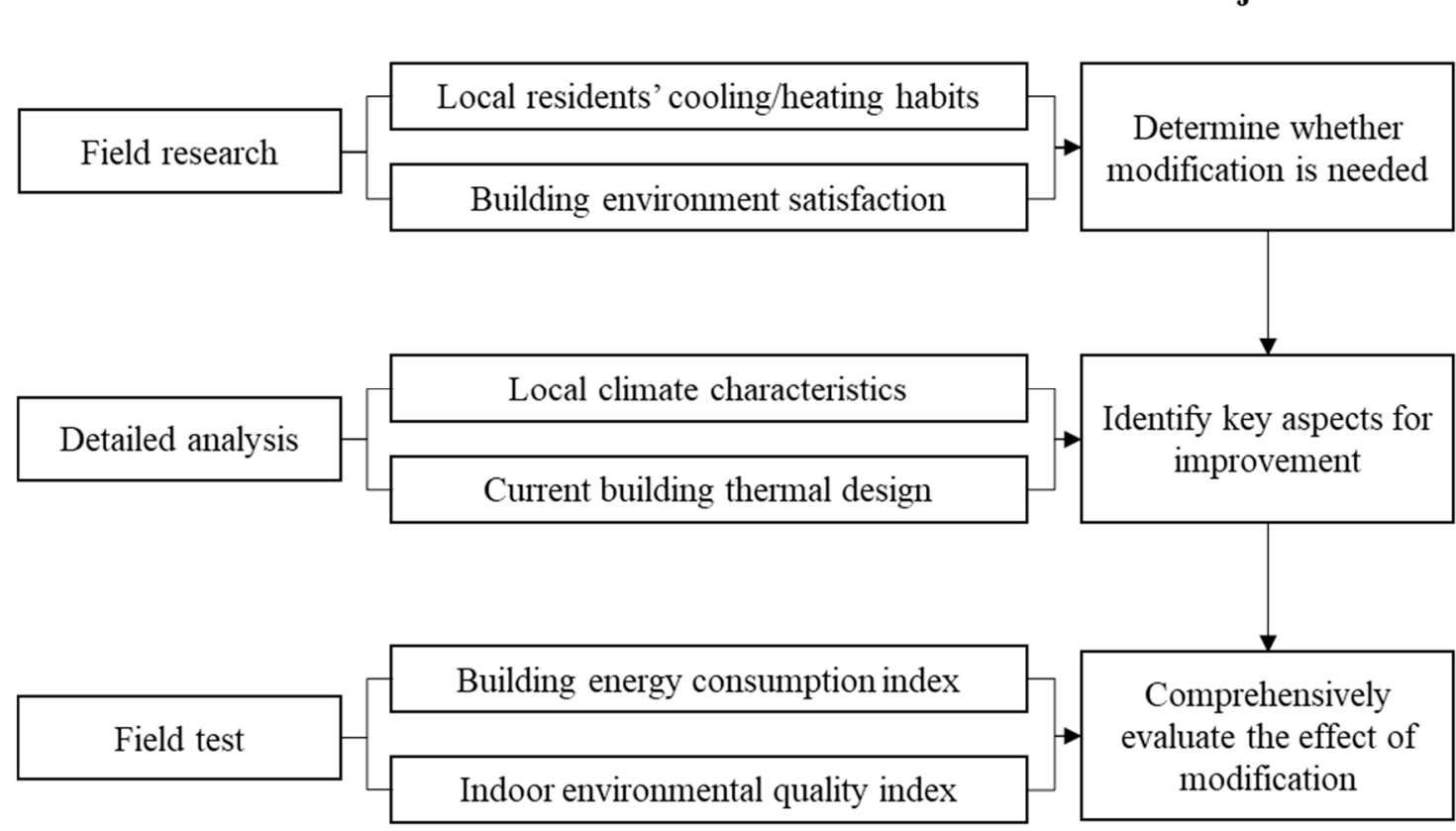

Figure 1. Flow chart of the modification method of building energy-saving design proposed in this study.

\subsection{Field Research}

The field study consists of two aspects: the real climatic characteristics of Panzhihua, and the cooling and heating methods and habits of local residents. Four districts and counties of Panzhihua City, namely Bingcaogang (East District), Miyi County, Renhe District, and Yanbian County, were selected to study the climatic characteristics. Locations of the districts and counties are shown in the map of Panzhihua (Figure 2). The hourly outdoor dry bulb temperature, relative humidity, and other parameters during a recent 10-year period (2009-2018) were analyzed. According to the climate zoning method in the Chinese national standard "Code for Thermal Design of Civil Building" [15], the average temperature of the coldest month, the average temperature of the hottest month, the number of heating degree days and the number of cooling degree days were counted as the main indicators of Panzhihua, thereby determining the actual climate zone of Panzhihua and thus the corresponding building energy-saving design schemes.

The cooling and heating habits of the residents were investigated through on-site inquiries and questionnaires. The survey was mainly conducted in Panzhihua City's main urban areas (East District, West District, and Renhe District) as well as in Yanbian County and Miyi County. The selected building types are all residential. Among them, 11 residential buildings were in the main urban areas, and there were 10 buildings in total in Miyi and Yanbian counties. The survey covered the months of cooling and heating, the types of air conditioning and heating equipment used, the time of day when the equipment was turned on, and the habits of opening windows and shading during the time when the equipment operated.

\subsection{Experimental Design}

A field test is an indispensable means to grasp the actual situation of Panzhihua, and to guarantee the expected energy-saving effect, building energy-saving designs based on field test data will be a more frequent target and become increasingly generalizable. The energy-saving design based on a field test is different from the traditional method of rigid adherence to design codes and norms. To verify its effect, this study modified the conventional energy-saving design scheme for Panzhihua according to the research 
results and a design scheme was implemented in an actual residential project with its effect verified through field tests.

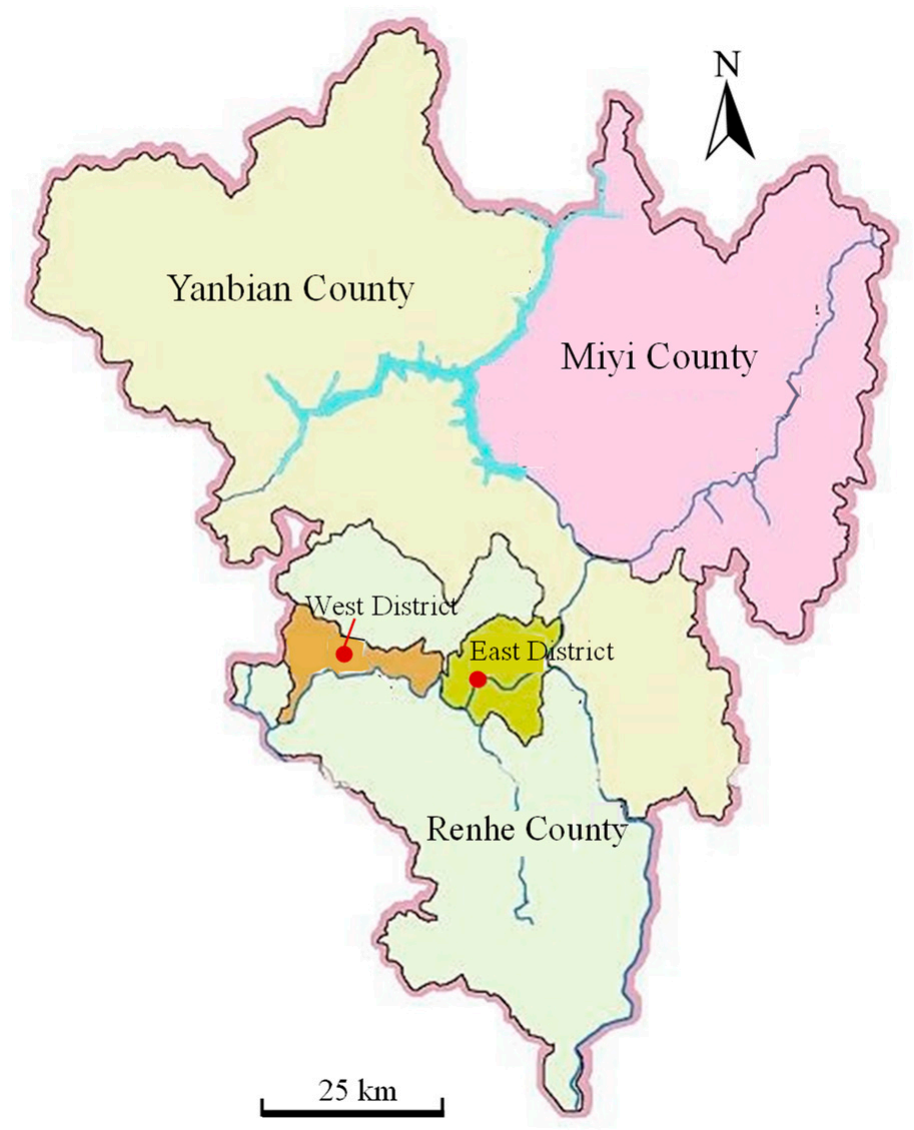

Figure 2. Map of Panzhihua City.

\subsubsection{Test Site}

The field test was conducted from June to August, 2020 in a tower building of a residential project in Renhe District, Panzhihua $\left(101.7^{\circ} \mathrm{E}, 26.5^{\circ} \mathrm{N}\right)$. The project, which consists of several tower-shaped high-rise buildings is very typical of modern urban residences in China. As mentioned, the main purpose of the field test is to evaluate the modified energy-saving scheme by analyzing its effect on the thermal environment and energy consumption. Therefore, two rooms of different orientations were selected from the sixth and eighth floors of the building as the experimental and control groups, respectively. The old energy-saving design scheme was used for the envelop structure of the room on the eighth floor, whereas the upgraded design scheme was adopted for the sixth floor. To minimize the influence of altitude, the two floors are reasonably close to each other. Meanwhile, the seventh floor helps to prevent interplay between the tested floors. The layout, which is shared by all the standard floors, is shown in Figure 3 with the tested rooms circled by dotted boxes. Field research shows that western sun exposure is a big concern in Panzhihua. Therefore, rooms on the western side which is more severely exposed to the sunset radiation are selected. As shown, the room $15^{\circ}$ toward the southeast is denoted as $\mathrm{C} 3$, whereas another room $75^{\circ}$ toward the southwest is denoted as $\mathrm{C} 4$. For instance, rooms on the sixth floor are noted as 6-C3 and 6-C4, respectively. 


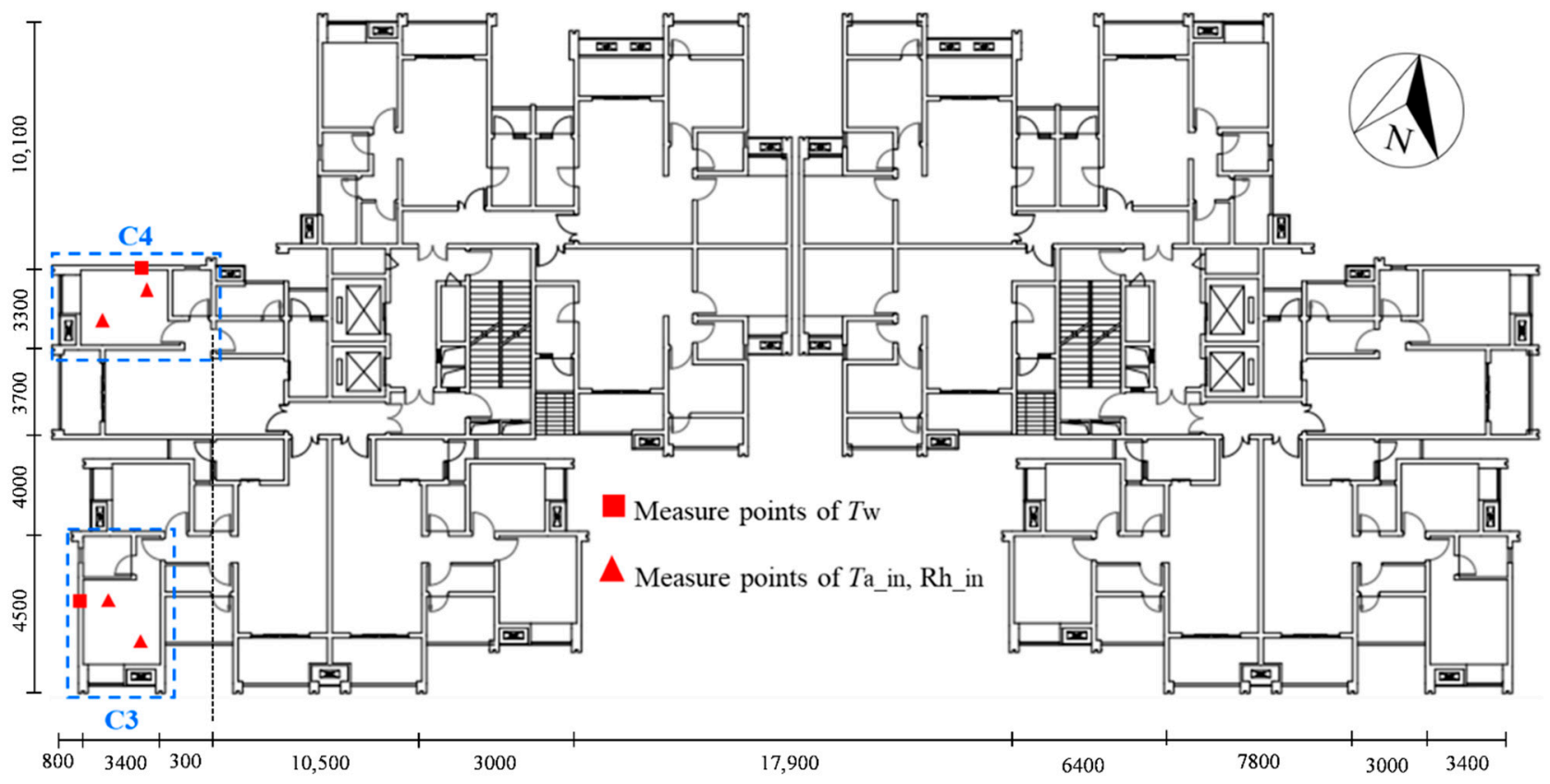

Figure 3. Locations of the tested rooms and measurement points for the wall temperature $\left(T_{\mathrm{w}}\right)$, indoor air temperature ( $T_{\mathrm{a} \_}$in), and relative humidity $\left(R h \_i n\right)$. Unit of dimensions in the figure is millimeter $(\mathrm{mm})$.

The measured parameters include the outdoor temperature (Ta_out) and relative humidity, indoor temperature ( $T$ a_in) and relative humidity $\left(R h \_\right.$in), outer wall surface temperature ( $\left.T w \_o u t\right)$, inner wall surface temperature ( $\left.T w \_i n\right)$, and daily electricity consumption of each room. Locations of the indoor measure points are marked in the image. Figure 4 shows photos of the test site.

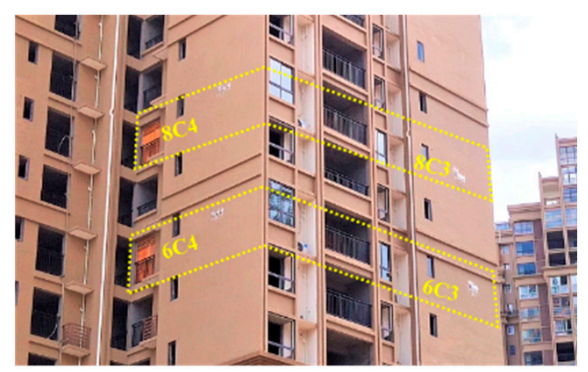

(a)

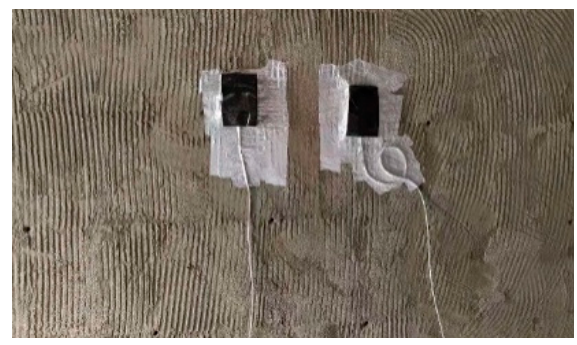

(c)

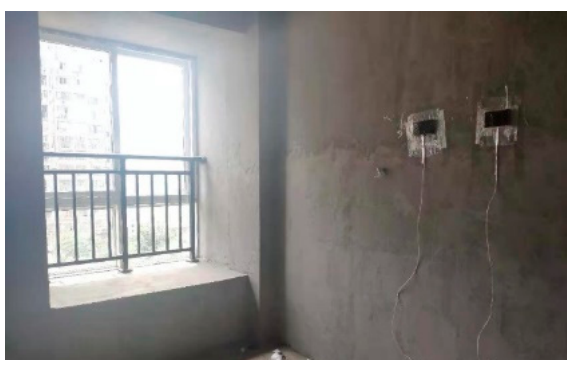

(b)

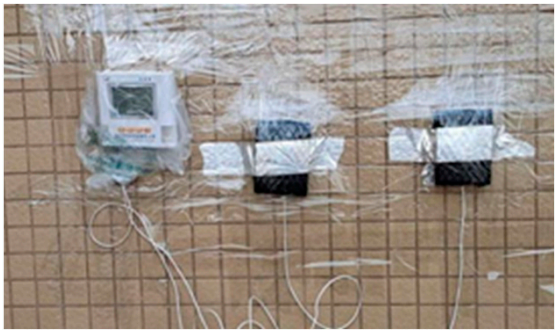

(d)

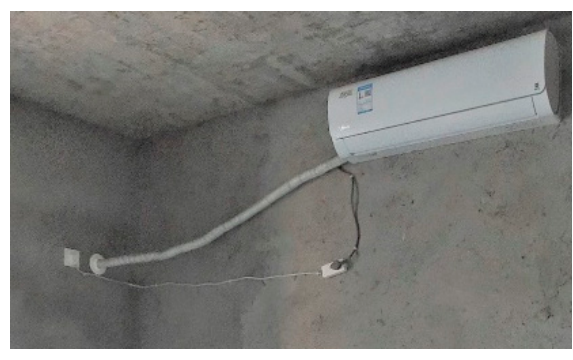

(e)

Figure 4. Photos of (a) exterior view of the tested rooms; (b) interior view of the tested rooms; (c) sensors mounted on the inside wall; (d) sensors mounted on the outside wall; (e) split air conditioner. 


\subsubsection{Measurement Approach}

Figure 5 shows the test flow diagram. The test was divided based on the renovation into the "baseline stage" and the "trial stage." The baseline stage was designed to study the inherent differences between the sixth floor and the eighth floor. Excluding these inherent differences, the differences resulting from the renovation were analyzed during the trial stage.

To reduce the interference, openings that connect the tested rooms with outdoor balconies were blocked with $200 \mathrm{~mm}$ hollow shale bricks. All doors and windows were closed and their edges sealed during the test. In addition, reserved mounting holes were sealed with a luting agent. Thus, the test was conducted in an enclosed and relatively independent space.

The project was under construction during the experiment thus avoiding the potential influences of the occupants and indoor equipment. Except for the tested rooms, all the other rooms were unused and not air-conditioned. For the tested rooms, because no electric appliances other than a split air conditioner were installed, the electricity is entirely consumed by the air conditioner, which operated for $24 \mathrm{~h}$ a day. Experimenters read the calibrated electricity meters at the same time each day to calculate the usage amount. For indoor temperature and humidity, each room has two measurement points that are settled $1500 \mathrm{~mm}$ above the floor. For the wall surface temperature, two thermometers with a horizontal distance of $50 \mathrm{~cm}$ were attached to each side of the wall with identical locations. There were two outdoor temperature and humidity measure points on the balcony of the sixth and eighth floors respectively, both set in the shade of the building. Temperaturehumidity recorders were placed in instrument shelters $1500 \mathrm{~mm}$ above the floor to avoid solar radiation. Information on the measurement equipment is listed in Table 1.

\section{Process}

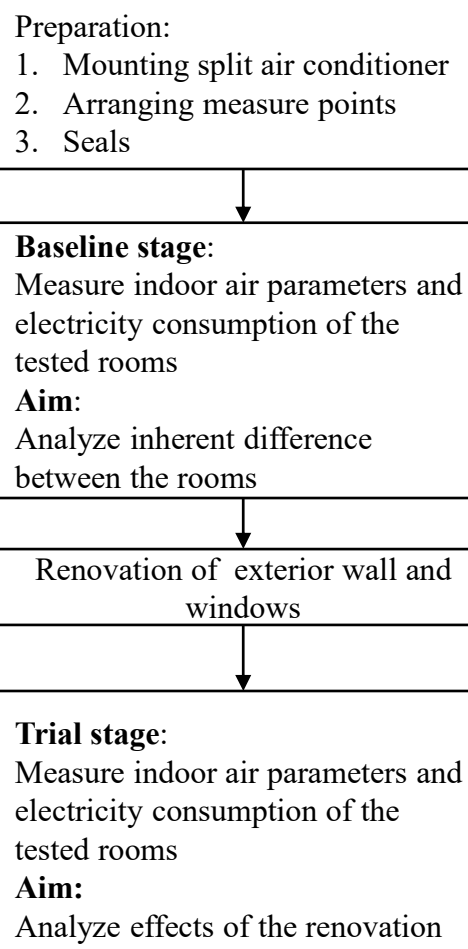

Aim:

Analyze effects of the renovation

Figure 5. Flow diagram of the field test.

\section{Duration}

6 days

4 days

9 days

1 to 2 month 
Table 1. Equipment in the tested rooms.

\begin{tabular}{cc}
\hline Equipment & Nominal Parameters \\
\hline $\begin{array}{c}\text { Thermometer } \\
\text { (L93-3, HangZhou Loggertech Co., Ltd.,Hangzhou,China) }\end{array}$ & Temperature: $-40-100{ }^{\circ} \mathrm{C}\left( \pm 0.5^{\circ} \mathrm{C}\right)$ Resolution: $0.1{ }^{\circ} \mathrm{C}$ \\
Temperature-humidity recorder & Temperature: $-40-100{ }^{\circ} \mathrm{C}\left( \pm 0.5^{\circ} \mathrm{C}\right)$ \\
(L95-2, HangZhou Loggertech Co., Ltd.,Hangzhou,China) & Relative humidity: $0-100 \%( \pm 3 \%)$ \\
\hline Split air conditioner & Capacity $(\mathrm{kW}): 3.50($ cooling $) / 5.45($ heating $)$ \\
(KFR-35GW, Midea Group Co., Ltd., Foshan, China) & Power $(\mathrm{kW}): 1.06($ cooling $) / 2.48($ heating $)$ \\
\hline
\end{tabular}

\subsection{Calculation of Standard Effective Temperature (SET*)}

The standard effective temperature SET* is based on the two-node model proposed by Gagge et al., [31]. Based on the lumped parameter theory, the model simplifies the human body into two nodes: the core layer and the skin layer. A portion of the heat generated by metabolism in the core layer is transferred to the skin layer through the blood flow and heat conduction, a portion is dissipated through respiration and external work, and the remaining portion is stored. The skin layer mainly dissipates heat through convection, sweat evaporation, a diffusive evaporation, and radiation. The SET* is defined as the air the temperature of a standard environment with a relativity humidity of $50 \%$, air velocity of $0.1 \mathrm{~m} / \mathrm{s}$, and radiant temperature identical to the air temperature. In a standard environment, the heat loss from the skin of a typical occupant is insignificant. In a standard environment, the heat loss from the skin of a typical occupant at an activity level of 1.0 is met and a clothing level of 0.6 clo is the same as that in the actual environment [32].

In this study, $\mathrm{SET}^{*}$ was chosen as the thermal comfort indicator rather than the predicted mean vote (PMV) for two reasons. First, the SET* can be applied under wider scenarios including dynamic conditions, [33] whereas the PMV is restricted to a steady state [34]. Second, the PMV solely predicts the psychological responses of the occupants without a reflection of the physiological index, e.g., the skin temperature and skin wetness. Previous studies have widely applied the SET* to evaluate the indoor thermal comfort in both air-conditioned and naturally ventilated buildings [35]. The method and a computer program for calculation of the SET* are provided in the ANSI/ASHRAE Standard 552017 [32].

\section{Results and Discussion}

\subsection{Analysis of Field Research}

\subsubsection{Climatic Characteristics}

The 10-year climate data statistics of various districts and counties were independently averaged, the average values of four districts and counties were calculated, and finally the parameter values used to represent the overall climate of Panzhihua City were obtained. The detailed statistics and relevant climate classification principles are shown in Table 2. According to the data, the average temperature of the coldest month in Panzhihua was $13.1^{\circ} \mathrm{C}$, and the average temperature of the hottest month was $25.7^{\circ} \mathrm{C}$. This is consistent with the characteristics of hot summer and warm winter zones. In addition, the average number of days at above $25^{\circ} \mathrm{C}(\mathrm{d} \geq 25)$ during the year is 100 , which also supports classifying this region into a hot summer and warm winter zone. Through further observation, the heating degree days was found to be $459.1^{\circ} \mathrm{C} \bullet$, which is in line with the characteristics of a hot summer and warm winter B zone (4B) [15].

In summary, based on the actual measurements and an analysis of outdoor climate data for 10 consecutive years, Panzhihua should be classified as a hot summer and warm winter B zone (4B) instead of the "mild climate zone" proposed in the national standard. It can be seen from the analysis of the characteristics of the two climate zones that mild zones have warm winters and cool summers, with the average temperature of the hottest month 
reaching no more than $25^{\circ} \mathrm{C}$. Therefore, the thermal insulation requirements of buildings are relatively low, and residents prefer to use natural ventilation to meet their thermal comfort needs during the summer [36].F However, some mild regions have lower winter temperatures, and thus it is necessary to consider a structural insulation or make full use of solar resources for heating. By contrast, the needs in a hot summer and warm winter zone are quite different from those in mild areas. During summer, thermal insulation is the top priority of the building energy saving design in this region. It is necessary to emphasize the shading design, airtightness of the windows and doors, and minimized heat gain in the building. However, the warm weather during winter allows appropriately reduce the need for thermal insulation. The above proves that the building thermal division provided in the national standard code can only provide a rough reference, and in the energy-saving design of an actual project, it is necessary to first check the measured meteorological data, and make the correct judgment of the climate zone. The correctness of the design principles can then be ensured and the effects of building energy saving can be achieved.

Table 2. 2009-2018 Statistical results of meteorological parameters in Panzhihua.

\begin{tabular}{|c|c|c|c|c|c|}
\hline Measurement & Location & 10-Year Average & 4-District Average & $\begin{array}{c}\text { Hot Summer and Warm } \\
\text { Winter B }\end{array}$ & Mild Climate \\
\hline \multirow{4}{*}{$t_{\min \cdot \mathrm{m}}\left[{ }^{\circ} \mathrm{C}\right]$} & Bingchaogang & 13.7 & \multirow{4}{*}{13.1} & \multirow{4}{*}{$10^{\circ} \mathrm{C} \leq t_{\min \cdot m}$} & \multirow{4}{*}{$0{ }^{\circ} \mathrm{C}<t_{\text {min.m }} \leq 13{ }^{\circ} \mathrm{C}$} \\
\hline & Miyi & 12.3 & & & \\
\hline & Renhe & 13.2 & & & \\
\hline & Yanbian & 13.2 & & & \\
\hline \multirow{4}{*}{$t_{\max . \mathrm{m}}\left[{ }^{\circ} \mathrm{C}\right]$} & Bingchaogang & 25.6 & \multirow{4}{*}{25.7} & \multirow{4}{*}{$25^{\circ} \mathrm{C}<t_{\text {max.m }} \leq 29^{\circ} \mathrm{C}$} & \multirow{4}{*}{$18^{\circ} \mathrm{C}<t_{\text {max.m }} \leq 25^{\circ} \mathrm{C}$} \\
\hline & Miyi & 25.4 & & & \\
\hline & Renhe & 26.3 & & & \\
\hline & Yanbian & 25.4 & & & \\
\hline \multirow{4}{*}{$H D D 18\left[{ }^{\circ} \mathrm{C} \bullet \mathrm{d}\right]$} & Bingchaogang & 401.4 & \multirow{4}{*}{459.1} & \multirow{4}{*}{$H D D 18<500$} & \multirow{4}{*}{$700 \leq H D D 18<2000$} \\
\hline & Miyi & 548.9 & & & \\
\hline & Renhe & 432.1 & & & \\
\hline & Yanbian & 454.0 & & & \\
\hline \multirow{4}{*}{$\mathrm{CDD} 26\left[{ }^{\circ} \mathrm{C} \bullet \mathrm{d}\right]$} & Bingchaogang & 171.0 & \multirow{4}{*}{152.2} & \multirow{4}{*}{ / } & \multirow{4}{*}{$C D D 26<10$} \\
\hline & Miyi & 105.2 & & & \\
\hline & Renhe & 201.2 & & & \\
\hline & Yanbian & 131.5 & & & \\
\hline \multirow{4}{*}{$\mathrm{d}_{\leq 5}[\mathrm{~d}]$} & Bingchaogang & 0.2 & \multirow{4}{*}{0.1} & \multirow{4}{*}{ / } & \multirow{4}{*}{$0 \leq \mathrm{d}_{\leq 5}<90$} \\
\hline & Miyi & 0.0 & & & \\
\hline & Renhe & 0.1 & & & \\
\hline & Yanbian & 0.0 & & & \\
\hline \multirow{4}{*}{$\mathrm{d}_{\geq 25}[\mathrm{~d}]$} & Bingchaogang & 104.2 & \multirow{4}{*}{100.0} & \multirow{4}{*}{$100 \leq \mathrm{d}_{\geq 25}<90$} & \multirow{4}{*}{ / } \\
\hline & Miyi & 88.4 & & & \\
\hline & Renhe & 113.9 & & & \\
\hline & Yanbian & 93.1 & & & \\
\hline
\end{tabular}

$t_{\text {min.m }}$ : Average temperature of the coldest month. $t_{\text {max.m }}$ : Average temperature of the hottest month. HDD18: Number of heating degree days. $C D D 26$ : Number of cooling degree days. $\mathrm{d}_{\leq 5}$ : Number of days at below $25^{\circ} \mathrm{C} . \mathrm{d}_{\geq 25}$ : Number of days at above $25^{\circ} \mathrm{C}$.

\subsubsection{Cooling and Heating Habits of Local Residents}

According to the site survey, all participating residential communities in Panzhihua adopt split air conditioning. The cooling season in Panzhihua area is long, usually lasting from April to August. The air conditioner is on during the daylight hours of 11:00-15:00 and during the nighttime hours of 20:00-22:00. Households with elderly people living alone are less likely to turn on the air conditioner during the summer, whereas the opposite is true for households with mainly young people or children. According to statistics, households with elderly people who live alone account for approximately $40 \%$ of the total surveyed households. By contrast, there is almost no heating demand in Panzhihua during the winter.

By analyzing the questionnaire data and compiling the interview results, the following information about the living habits of residents is summarized: In terms of air-conditioning 
usage, the frequency of using air conditioners in residential buildings in Panzhihua largely depends on the age of the residents. Nearly all residents in the community that participated in the survey clearly indicated that the elderly are more reluctant to use air conditioners for cooling and heating. During summer, they prefer to use natural ventilation or electric fans, whereas during winter they keep warm by adding more clothes and do not pay much attention to thermal comfort. Previous studies have shown that residents can enhance their adaptability to the thermal environment through behavioral and physiological regulatory mechanisms [37,38]. By contrast, young people and residents with children seek higher thermal comfort and are accustomed to using air conditioners for cooling and heating. In terms of window opening habits, Panzhihua residents generally pay attention to indoor air quality and are used to opening windows for ventilation regardless of air conditioner operation. In terms of shading, the strong solar radiation in Panzhihua has led to serious western exposure in many buildings, particularly in high-rise buildings with glass curtain walls, where the top floor is often overheated in the west and the air conditioning load increases dramatically. Therefore, the local residents usually add shades to the external windows to cope with the western exposure.

\subsection{Modified Building Energy-Saving Design}

According to the analysis of the climate and cooling and heating habits of residents in Panzhihua in Section 3.1, it was found that local residents are accustomed to natural ventilation, and the passive ventilation design of buildings should be optimized or ventilation devices should be installed in poorly ventilated areas. At the same time, Panzhihua has severe western sun exposure, and attention should be paid to strengthening the shading performance of the external window. By contrast, results show that interior thermal insulation is not welcomed. Originally, interior thermal insulation with advantages in resisting extreme weather [39], preventing condensation [40], and lowering cost is widely used, because the design codes mistakenly classify Panzhihua as mild climate region [15]. However, the fact is that Panzhihua exhibits distinctive features of hot summer and warm winter with almost no heating demand. Many residents prefer to remove interior thermal insulation to expand usable area.

Accordingly, the focus of the building energy-saving design improvement in this study is to strengthen the ability of the envelope structure to block the heat gain from solar radiation, and relatively reduce the requirements on its thermal insulation performance, thereby saving energy and obtaining economic benefits at the same time.

The renovation mainly involves exterior walls and windows. For the sixth floor, the originally mounted insulation layer composed of a $30 \mathrm{~mm}$ foam board and $5 \mathrm{~mm}$ anti-crack mortar, is canceled. In addition, low emissivity (Low-E) glass and black external shade are applied to the windows, and the window form changes from a sash window to a casement window. The eighth floor, which is defined as the control group, maintains the original envelope design. Specific thermal parameters and structures of the building envelope are listed in Table 3. The canceled insulation layer is highlighted in bold. As shown, the absence of insulation increases the heat transfer coefficient from $1.2 \mathrm{~W} /\left(\mathrm{m}^{2} \mathrm{~K}\right)$ to $2.8 \mathrm{~W} /\left(\mathrm{m}^{2} \mathrm{~K}\right)$. However, modified windows exhibit a better solar radiation block performance and decreased heat transfer coefficient.

\subsection{Effects on Thermal Environment}

\subsubsection{Outer Surface Temperature of Wall}

Figure 6 shows the monitoring data of the outer wall surface temperature and outdoor air temperature of the four rooms for six consecutive days after the renovation, and Table 4 details the peaks of the outer wall surface temperature, outdoor air temperature, and appearance of the peak values for six consecutive days of testing. As shown in the figure, the peak outer wall surface temperature of the two rooms numbered C4 is significantly higher than that of the rooms numbered $\mathrm{C} 3$, and the average differences of peak $T \mathrm{w} \_$out between the two rooms on the sixth and eighth floors were $3.6^{\circ} \mathrm{C}$ and $2.7^{\circ} \mathrm{C}$, respectively. 
In addition, the time at which the peak values of the wall surface temperature occurred also differed significantly between rooms with different orientations: The peak of C3 usually occurred at approximately 15:00, which was close to the time of peak outdoor air temperature, whereas the peak of $\mathrm{C} 4$ usually occurred at between 17:00 and 18:30. This phenomenon indicates that the fluctuation of the outer wall temperature of rooms toward south was dominated by the fluctuation of outdoor air temperature, whereas the rooms toward west were affected more by the western sun exposure. The high intensity solar radiation in the Panzhihua area can make a considerable temperature difference between the peak temperature of the outer wall surface of a western-exposed room and a non-western-exposed room.

Table 3. Materials and thermal parameters of building envelope of the sixth and eighth floors.

\begin{tabular}{|c|c|c|c|c|c|}
\hline Floor & Part & ${ }^{\mathrm{a}} \mathrm{K}\left[\mathrm{W} / \mathrm{m}^{2} \mathrm{~K}\right]$ & b SHGC & & Material (Thickness) \\
\hline \multirow[t]{2}{*}{8} & Wall & 1.20 & - & (2) & $\begin{array}{l}\text { Thermal bridge: cement mortar }(20 \mathrm{~mm})+\text { reinforced concrete } \\
(200 \mathrm{~mm})+\text { cement mortar }(20 \mathrm{~mm})+\text { foam insulation board } \\
(30 \mathrm{~mm})+\text { anti-crack mortar }(5 \mathrm{~mm}) \\
\text { Main structure: cement mortar }(20 \mathrm{~mm})+\text { sintered self-insulating } \\
\text { brick }(200 \mathrm{~mm})+\text { cement mortar }(20 \mathrm{~mm})+\text { foam insulation board } \\
(30 \mathrm{~mm})+\text { anti-crack mortar }(5 \mathrm{~mm})\end{array}$ \\
\hline & Window & 3.20 & 0.71 & $\begin{array}{l}(1) \\
(2)\end{array}$ & $\begin{array}{l}\text { Sash window: insulating metal section }+ \text { transparent glass }(6 \mathrm{~mm})+ \\
\text { air layer }(12 \mathrm{~mm})+\text { transparent glass }(6 \mathrm{~mm}) \\
\text { Shading device: none }\end{array}$ \\
\hline \multirow[t]{2}{*}{6} & Wall & 2.80 & - & $\begin{array}{l}(1) \\
(2)\end{array}$ & $\begin{array}{l}\text { Thermal bridge: cement mortar }(20 \mathrm{~mm})+\text { reinforced concrete } \\
(200 \mathrm{~mm})+\text { cement mortar }(20 \mathrm{~mm}) \\
\text { Main structure: cement mortar }(20 \mathrm{~mm})+\text { sintered self-insulating } \\
\text { brick }(200 \mathrm{~mm})+\text { cement mortar }(20 \mathrm{~mm})\end{array}$ \\
\hline & Window & 2.50 & 0.35 & $\begin{array}{l}(1) \\
(2)\end{array}$ & $\begin{array}{l}\text { Casement window: insulating metal section + Low-E glass }(6 \mathrm{~mm}) \\
\text { + air layer }(12 \mathrm{~mm})+\text { transparent glass }(6 \mathrm{~mm}) \\
\text { Shading device: black external shade }\end{array}$ \\
\hline
\end{tabular}

${ }^{a}$ : Heat transfer coefficient. ${ }^{b}$ : Solar heat gain coefficient.

By contrast, it can be seen from Figure 6 that the overall outer wall surface temperature of the rooms on the eighth floor is higher than that on the sixth floor throughout the day. Figure 7 shows the difference between the average temperature of the outer wall of the rooms with the same orientation on the six and eighth floors during the day and night. During the day, the difference between the two is smaller, with the average temperature difference between $8-\mathrm{C} 3$ and $6-\mathrm{C} 3$ being $0.82{ }^{\circ} \mathrm{C}$, and the average temperature difference between $8-\mathrm{C} 4$ and $6-\mathrm{C} 4$ being $0.79{ }^{\circ} \mathrm{C}$. This is mainly due to the rooms on higher floors receiving more sunlight, thereby increasing the outer wall temperature; at night, however, the rooms subjected to western exposure in the evening, namely, 8-C4 and 6-C4, had a much higher temperature difference in the outer wall surface than that during the daytime, with an average value of $1.2{ }^{\circ} \mathrm{C}$ and a maximum value of $2.1{ }^{\circ} \mathrm{C}$. As a possible reason for this, the room on the eighth floor has no external shading and the wall has internal insulation. A large amount of direct radiation through the glass is absorbed by the indoor surface and stored in the wall. It is released again when the outdoor temperature decreases at night, making the outer wall surface temperature of 8-C4 much higher than that of 6-C4, and the rate of decline is slower. The $\mathrm{C} 3$ rooms are less exposed to solar radiation overall, and thus the day-night difference of the outer wall surface temperature between 8-C3 and 6-C3 is not obvious. This difference may have a different impact on the energy 
consumption; in other words, the same envelope retrofit measures may cause the energy consumption to increase in one orientation and decrease in the other. A detailed analysis of the energy consumption will be presented later.

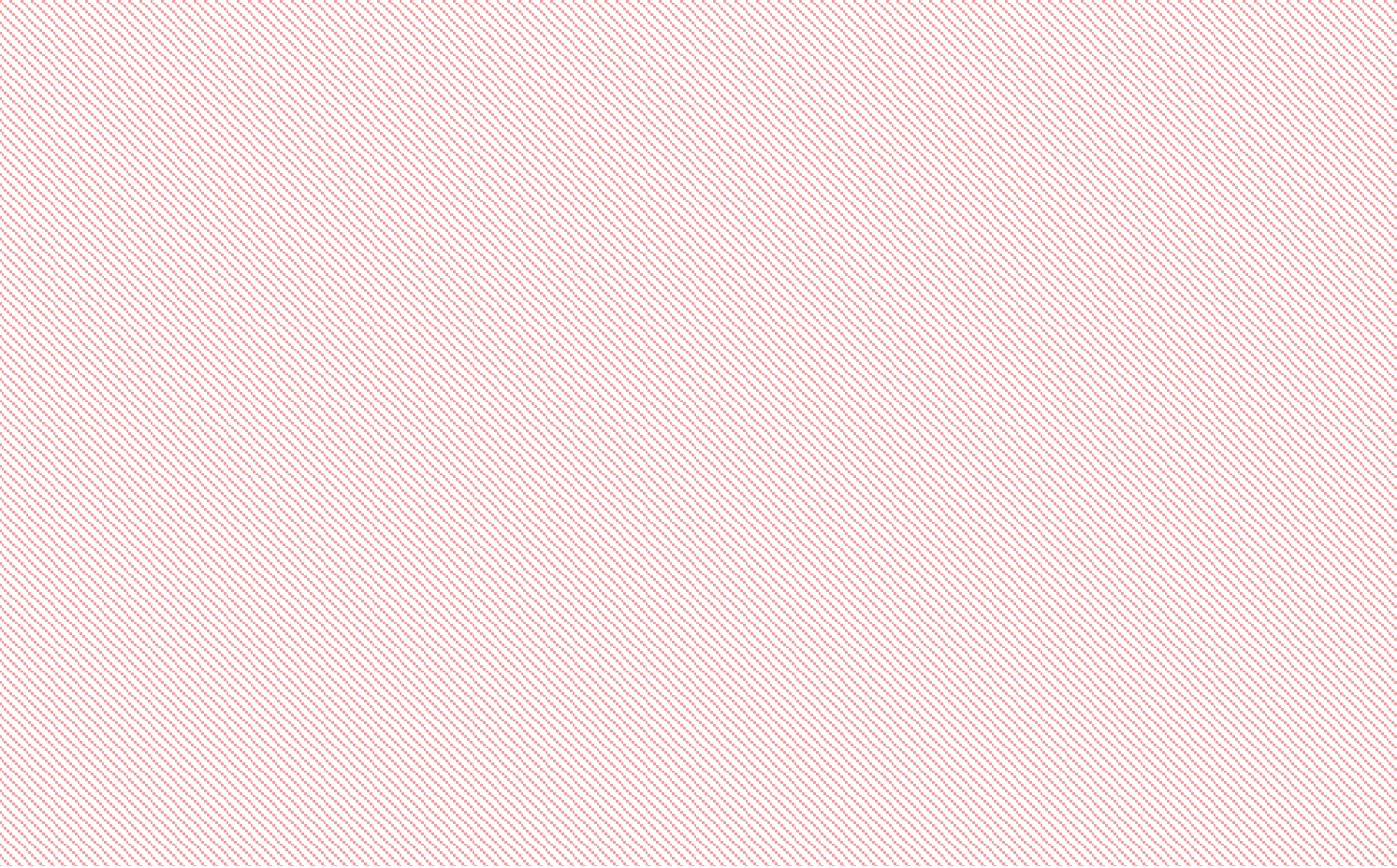

Figure 6. Outer wall surface temperature (Tw_out) and outdoor air temperature (Ta_out) of rooms 6-C3, 6-C4, 8-C3, and $8-\mathrm{C} 4$.

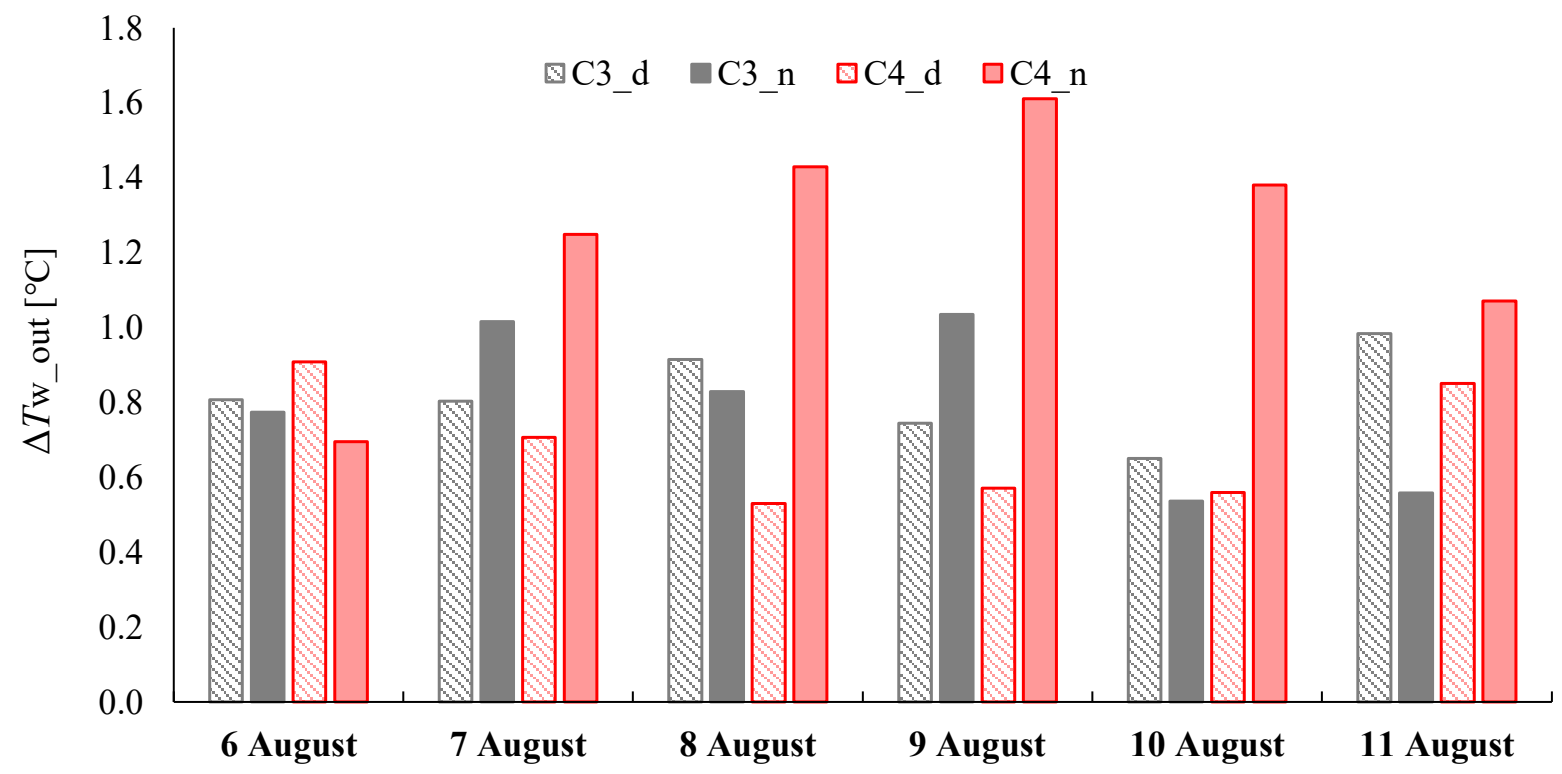

Figure 7. Average difference in outer wall surface temperature between rooms during the day (C3_d, C4_d) and night (C3_n, C4_n) (6-C3 vs. 8-C3, 6-C4 vs. 8-C4). 
Table 4. The peaks of the outer wall surface temperature and outdoor air temperature, and the corresponding time of appearance for each room.

\begin{tabular}{|c|c|c|c|c|c|}
\hline Test Day & Room & $\operatorname{Max} T_{w_{-} \text {out }}{ }^{\circ} \mathrm{C}$ & Appear Time & $\operatorname{Max} T_{a_{a} \_ \text {out }}{ }^{\circ} \mathrm{C}$ & Appear Time \\
\hline \multirow{4}{*}{6 August } & $6-\mathrm{C} 3$ & 35.4 & $15: 00$ & \multirow{4}{*}{46.1} & \multirow{4}{*}{$14: 20$} \\
\hline & $8-\mathrm{C} 3$ & 36.2 & $15: 00$ & & \\
\hline & $6-C 4$ & 39.6 & $18: 40$ & & \\
\hline & $8-C 4$ & 39.2 & $18: 50$ & & \\
\hline \multirow{4}{*}{7 August } & $6-\mathrm{C} 3$ & 32.6 & $15: 30$ & \multirow{4}{*}{37.5} & \multirow{4}{*}{$14: 40$} \\
\hline & $8-\mathrm{C} 3$ & 33.8 & $15: 20$ & & \\
\hline & $6-C 4$ & 35.3 & $17: 10$ & & \\
\hline & $8-C 4$ & 35.7 & $17: 30$ & & \\
\hline \multirow{4}{*}{8 August } & $6-\mathrm{C} 3$ & 32.5 & $16: 10$ & \multirow{4}{*}{35.6} & \multirow{4}{*}{$15: 10$} \\
\hline & $8-\mathrm{C} 3$ & 33.8 & $16: 20$ & & \\
\hline & 6-C4 & 37.6 & $17: 10$ & & \\
\hline & $8-\mathrm{C} 4$ & 37.3 & $17: 30$ & & \\
\hline \multirow{4}{*}{9 August } & $6-\mathrm{C} 3$ & 30.7 & $15: 20$ & \multirow{4}{*}{35.7} & \multirow{4}{*}{$14: 30$} \\
\hline & $8-\mathrm{C} 3$ & 31.9 & $15: 10$ & & \\
\hline & $6-C 4$ & 34.2 & $17: 20$ & & \\
\hline & 8-C4 & 34.2 & $17: 30$ & & \\
\hline \multirow{4}{*}{10 August } & $6-\mathrm{C} 3$ & 32.5 & $15: 00$ & \multirow{4}{*}{41.1} & \multirow{4}{*}{$14: 50$} \\
\hline & $8-\mathrm{C} 3$ & 33.2 & $15: 10$ & & \\
\hline & $6-C 4$ & 35.6 & $18: 30$ & & \\
\hline & $8-C 4$ & 36.1 & $18: 30$ & & \\
\hline \multirow{4}{*}{11 August } & $6-\mathrm{C} 3$ & 31.2 & $16: 50$ & \multirow{4}{*}{37.0} & \multirow{4}{*}{$14: 30$} \\
\hline & $8-\mathrm{C} 3$ & 32.7 & $17: 00$ & & \\
\hline & $6-C 4$ & 35.2 & $17: 10$ & & \\
\hline & $8-C 4$ & 35.0 & $17: 10$ & & \\
\hline
\end{tabular}

\subsubsection{Indoor and Outdoor Temperature Difference}

Figure 8 shows the variation curves of the temperature difference between the inner and outer surfaces of the exterior wall, and the temperature difference between indoor and outdoor temperatures.

First, the results of 6-C3 and 8-C3 were analyzed. During the day, the testers regularly adjusted the temperature setting of the air conditioner to ensure that the indoor air temperature of the four rooms was almost the same. Therefore, the indoor and outdoor temperature differences between the two rooms were extremely close during the day; however, there was no adjustment at night, and the indoor and outdoor temperature difference for 6-C3 was smaller than that of 8-C3 because the removal of thermal insulation layer caused reduction in thermal resistance of the walls on the sixth floor. This phenomenon needs to be discussed according to the situation, when the outdoor temperature at night is still extremely high during the hot summer, the indoor temperature of 6-C3 will be higher. However, during the cool season at night, the outdoor temperature is quite low (e.g., the third and fourth days, as shown in Figure 7), and the actual room has internal heat sources such as occupants and lighting. The indoor heat may be dissipated to the outside. At this time, the wall of 6-C3 will be more conducive to heat dissipation, reducing the load of the air conditioning. On the other hand, when the difference between the indoor and outdoor air temperatures was roughly equivalent, the inner wall temperature of 6-C3 was higher than that of 8-C3. The temperature difference between the inner and outer walls of the two rooms was significantly smaller than the difference between indoor and outdoor air temperatures, and their fluctuations were basically synchronized.

The pattern of 6-C4 and 8-C4 is opposite to that of the other two rooms discussed above. At night, the indoor temperature of 8 - $\mathrm{C} 4$ was higher. In addition, the temperature difference between the inner and outer walls of 6-C4 was quite similar to or even larger than 
that of 8-C4 during the daytime when the radiation is the strongest, and was significantly smaller than that of 8-C4 at night. For the entire day, the temperature difference between the inner and outer walls of $6-\mathrm{C} 4$ and $8-\mathrm{C} 4$ is not as obvious as that of $6-\mathrm{C} 3$ and $8-\mathrm{C} 3$. At the same time, the temperature difference between the inner and outer walls of room $\mathrm{C} 4$ is similar to the temperature difference between the indoor and outdoor air temperatures, and the fluctuation trends of the two were not completely synchronized.

The above phenomenon reveals once again the essential difference between room C3 and room $\mathrm{C} 4$ in the composition of the air-conditioning load, that is, the former comes mainly from the heat transfer of the envelope caused by the difference between the indoor and outdoor temperatures, whereas the latter contains a considerable part of the solar radiation heat. This can be confirmed by the temperature difference between the inner and outer walls and the temperature difference between the indoor and outdoor air temperatures. For room C3, the outer wall receives less solar radiation, so its temperature is usually lower than the outdoor air temperature. The heat transfer starts from the outdoor air and ends with the indoor air. Owing to the thermal resistance, as two intermediate nodes, the temperature difference between the side walls must be less than that between the starting points. By contrast, after the outer surface of the wall absorbs a large amount solar radiation, the wall temperature may exceed the outdoor air temperature. There is a certain delay in temperature increase of the inner wall, making the temperature difference between the two sides of the wall clearly enlarged. In this case, a portion of the radiation energy absorbed by the outer wall surface is stored in the wall body, causing its temperature to increase, with some of the heat transmitted into the room, and some dissipated outdoors.

The reason for the higher indoor temperature of 8-C4 at night is analyzed as follows. As shown in the floor plan (Figure 3), the exterior window of C4 is toward the west. Room 8-C4 does not apply any shading measures but uses ordinary transparent glass, whereas the entire window surface of 6-C4 is tightly covered by external shade and the exterior window uses Low-E glass. During the test, it was found that a large amount of direct solar radiation entered the room through the exterior window of 8-C4. This part of the radiation was first absorbed by the inner surface of the room to heat up the wall surface, and then heated up the indoor air through convection. In other words, the high temperature of the inner wall of 8-C4 is mainly due to the direct sunlight rather than the heat transfer from the wall. In this case, the insulation layer has little effect, and thus the temperature difference between the inner and outer walls of 8-C4 and 6-C4 during the day is similar. In addition, the insulation layer makes the heat absorbed by the wall during the daytime more difficult to diffuse outward, resulting in a high indoor air temperature of 8-C4 at night.

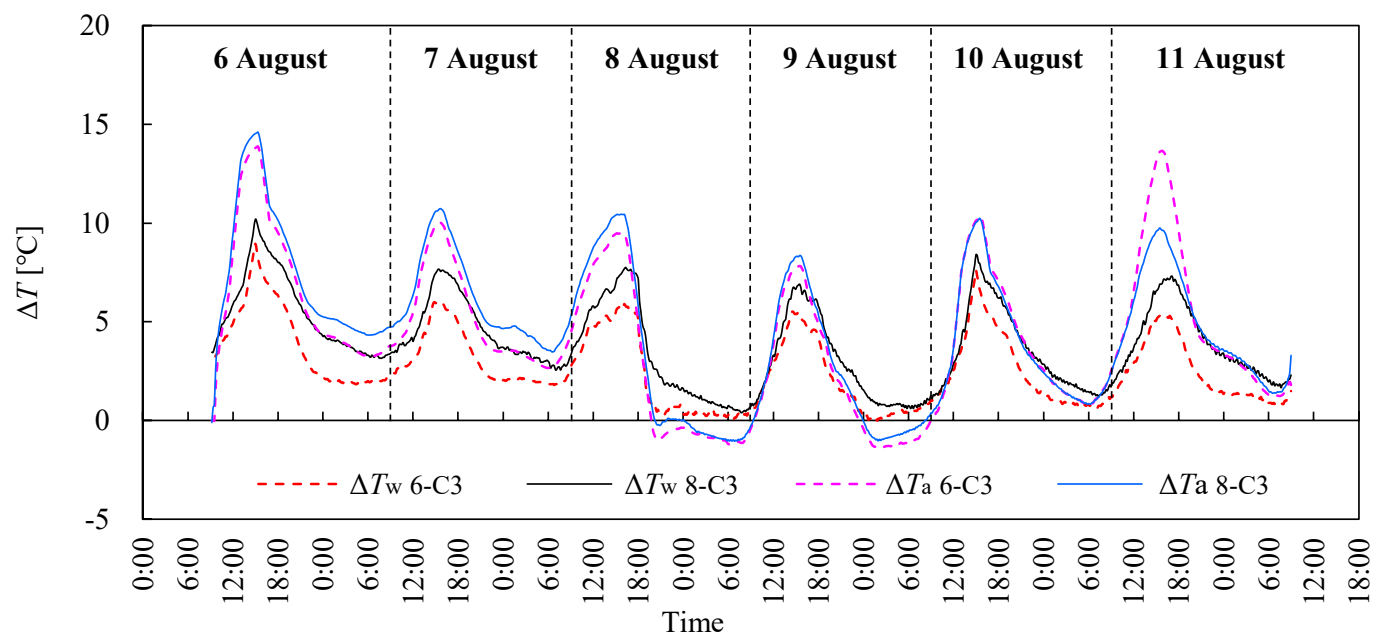

(a) 6 -C3 vs. $8-\mathrm{C} 3$

Figure 8. Cont. 


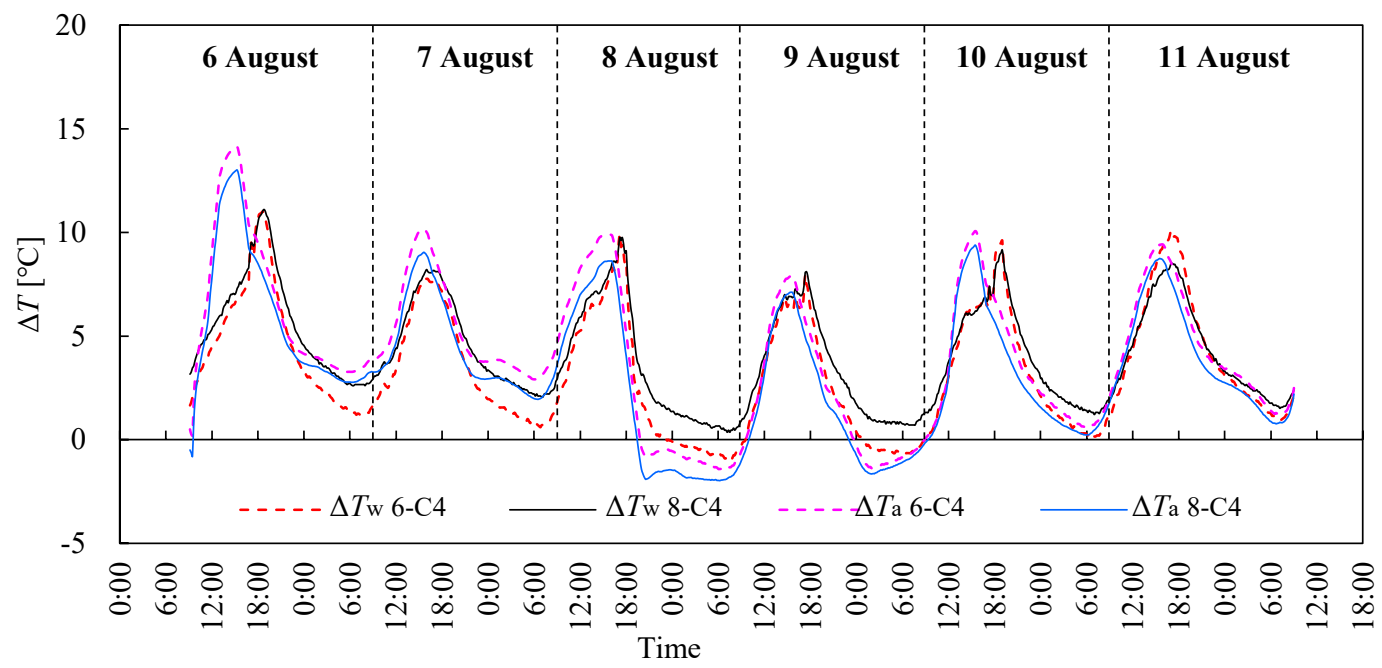

(b) 6-C4 vs. 8-C4

Figure 8. Variation curves of temperature differences between indoors and outdoors $(\triangle T \mathrm{~T})$ and the outer and inner surfaces of the exterior wall $(\Delta T w)$ for (a) 6-C3 and 8-C3 and (b) 6-C4 and 8-C4.

\subsubsection{Standard Effective Temperature (SET*)}

Based on the analysis results, the envelope renovation will affect both the indoor air temperature and the wall temperature, which contribute to human thermal comfort by affecting the convective and radiant heat dissipation of the human body, respectively. Thus, the SET* thermal comfort index, which combines the influence of $T a \_i n$ and the inner wall surface temperature Tw_in, is introduced. Table 5 shows the SET* values calculated by the method specified in ASHRAE Standard 55-2013, where 06:00 to 19:00 is defined as daytime and 19:00 to 06:00 the following day is defined as nighttime, which are divided mainly based on the presence of significant solar radiation. The parameter $\mathrm{Tr}$ refers to the 'mean radiation temperature', which is defined as the temperature of a uniform, black enclosure that exchanges the same amount of heat by radiation with the occupant as the actual surroundings [32]. This study obtained the Tr by inputting inner wall surface temperatures and room size information into the calculation program of SET*

Because the air conditioners were always on, all four rooms meet the thermal comfort requirements most of the time. A comparison of the daytime and nighttime data reveals that the SET* was higher at night. This is because the thermal inertia of the walls in this residential project is large. The highest inner wall surface temperature typically appears at approximately 19:30, and the inner wall surface temperatures at night are generally higher, resulting in higher average radiant temperatures. Comparing the two groups of rooms with the same orientation on the sixths and eighth floors respectively, the SET ${ }^{*}$ of 6-C3 is generally higher than that of 8-C3, mainly owing to the higher average radiant temperature. However, the SET* of 8-C4 is higher than that of 6-C4, with the air temperature and average radiant temperature both contributing. In other words, the room facing toward the south feels warmer after the retrofit than before, whereas the opposite is true for the room facing toward the west. The analysis of the specific causes was described in the previous section and will not be repeated. It should be noted that the difference in the SET* between the two rooms for comparison is usually no more than $0.5^{\circ} \mathrm{C}$. In fact, previous field tests show that occupants can have much wider thermal comfort zone than that suggested by the standards [41]. Thus, it can be argued that the change in thermal comfort caused by the envelope modifications is inconsequential. 
Table 5. Daytime and nighttime SET* of the investigated rooms during the test.

\begin{tabular}{|c|c|c|c|c|c|c|c|c|c|}
\hline \multirow{2}{*}{ Test Day } & \multirow{2}{*}{ Room } & \multicolumn{4}{|c|}{ Daytime } & \multicolumn{4}{|c|}{ Nighttime } \\
\hline & & $T_{\mathrm{a}}{ }^{\circ} \mathrm{C}$ & $T_{\mathrm{r}}^{\circ} \mathrm{C}$ & RH \% & $\mathrm{SET}^{* \circ} \mathrm{C}$ & $T_{\mathrm{a}}{ }^{\circ} \mathrm{C}$ & $T_{\mathrm{r}}{ }^{\circ} \mathrm{C}$ & RH \% & SET $^{* \circ} \mathrm{C}$ \\
\hline \multirow{4}{*}{6 August } & $6-C 3$ & 24.8 & 26.0 & 51 & 25.0 & 24.4 & 26.5 & 47 & 25.1 \\
\hline & $8-\mathrm{C} 3$ & 24.0 & 25.8 & 49 & 24.5 & 24.1 & 26.0 & 51 & 24.7 \\
\hline & $6-C 4$ & 24.6 & 26.8 & 48 & 25.4 & 24.6 & 27.1 & 49 & 25.6 \\
\hline & 8-C4 & 25.6 & 26.9 & 44 & 25.8 & 25.5 & 27.3 & 45 & 26.0 \\
\hline \multirow{4}{*}{7 August } & $6-C 3$ & 24.4 & 25.1 & 57 & 24.4 & 24.6 & 25.8 & 58 & 24.9 \\
\hline & $8-\mathrm{C} 3$ & 24.0 & 25.0 & 55 & 24.1 & 24.1 & 25.4 & 55 & 24.4 \\
\hline & $6-C 4$ & 24.3 & 25.5 & 58 & 24.6 & 24.4 & 26.4 & 58 & 25.2 \\
\hline & $8-C 4$ & 24.9 & 25.8 & 48 & 24.9 & 24.9 & 26.3 & 50 & 25.2 \\
\hline \multirow{4}{*}{8 August } & $6-C 3$ & 24.0 & 25.0 & 59 & 24.2 & 24.2 & 26.1 & 57 & 24.9 \\
\hline & $8-C 3$ & 24.1 & 24.9 & 57 & 24.1 & 24.3 & 25.5 & 55 & 24.6 \\
\hline & 6-C4 & 24.3 & 25.5 & 61 & 24.6 & 24.4 & 26.5 & 58 & 25.2 \\
\hline & 8-C4 & 24.8 & 25.6 & 51 & 24.8 & 25.1 & 26.6 & 51 & 25.5 \\
\hline \multirow{4}{*}{9 August } & $6-C 3$ & 23.0 & 25.6 & 50 & 24.0 & 25.0 & 26.6 & 55 & 25.5 \\
\hline & $8-C 3$ & 24.4 & 25.4 & 54 & 24.5 & 24.7 & 26.0 & 54 & 25.0 \\
\hline & $6-C 4$ & 24.6 & 25.4 & 61 & 24.7 & 24.8 & 26.3 & 58 & 25.3 \\
\hline & 8-C4 & 25.2 & 26.2 & 50 & 25.3 & 25.5 & 27.0 & 51 & 25.9 \\
\hline \multirow{4}{*}{10 August } & $6-C 3$ & 25.8 & 26.6 & 58 & 25.9 & 26.4 & 27.5 & 60 & 26.9 \\
\hline & $8-C 3$ & 25.4 & 26.2 & 62 & 25.6 & 25.7 & 26.8 & 62 & 26.1 \\
\hline & $6-C 4$ & 26.0 & 26.3 & 62 & 25.9 & 26.3 & 27.4 & 63 & 26.9 \\
\hline & 8-C4 & 25.5 & 26.6 & 50 & 25.7 & 25.6 & 27.1 & 50 & 26.0 \\
\hline
\end{tabular}

Tr: Mean radiation temperature.

\subsection{Effects on Energy Consumption}

It is inappropriate to directly compare the energy consumption of the two sets of rooms during the trial stage, because the rooms on the eighth floor are not completely the same as the rooms on the sixth floor, and their energy consumption cannot fully represent the energy consumptions of the rooms on the sixth floor without renovation. Therefore, the method of examining the effect of envelope renovation on the energy consumption is as follows: first, the energy consumption function relationships of 8-C3 (8-C4) and 6-C3 (6-c4) are fitted using the test data at the baseline stage, as shown in Figure 9. Subsequently, the energy consumptions of 8-C3 and 8-C4 during the trial period are taken as independent variables to calculate the energy consumptions of 6-C3 and 6-C4 without renovation respectively. The calculated energy consumptions are labeled "corrected energy consumption" and recorded as *E6-C3 and *E6-C4. Finally, the actual energy consumptions (E6-C3 and E6-C4) are compared with *E6-C3 and *E6-C4 to determine the increase or decrease of energy consumption after the renovation.

A comparison of the electricity consumption is shown in Figure 10. The diagonal line, which is the trajectory of points with the same horizontal and vertical coordinate values, divides the coordinate space into two parts. Thus, the points distributed in the higher part means that the corrected electricity consumption is higher than the actual consumption, and the electricity consumption is reduced after renovation, and vice versa. During the baseline stage, the envelope structure of the sixth and eighth floors are identical, and the eighth floor has a slightly higher overall energy consumption than the sixth floor because it receives more sunlight. It can be seen from the figure that the electricity consumption of 6-C3 has increased significantly after the renovation. The average value of E6-C3 is 20.7\% higher than that of *E6-C3. If we directly compare 6-C3 and 8-C3, the average value of E6-C3 is 16\% higher than that of E8-C3. By contrast, the difference between E6-C4 and *E6-C4 is extremely small, the mean value of the former is approximately $11 \%$ smaller than that of the latter. Considering that there is a certain error in the fitting formula, and Figure $9 \mathrm{~b}$ also shows the existence of individual outliers, it can be concluded that there is no significant change in energy consumption after the renovation of 6-C4. It needs to be noted that, this conclusion is based on the fact that the thermal environment maintained high quality requirements. Considering that residents can expand their thermal comfort 
range through multiple adaptation mechanisms, the renovation is expected to generate considerable energy saving potential [42].

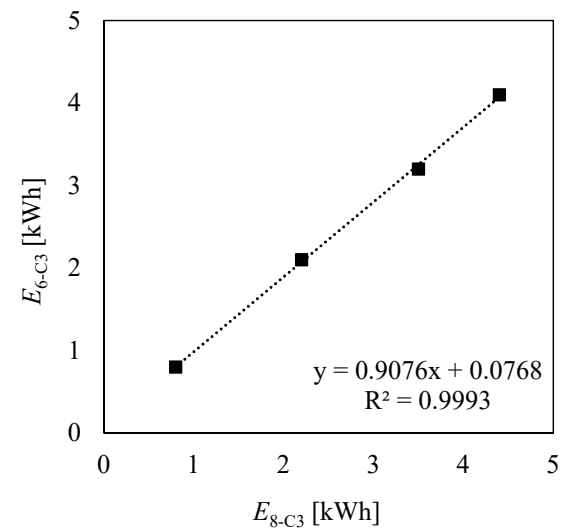

(a)

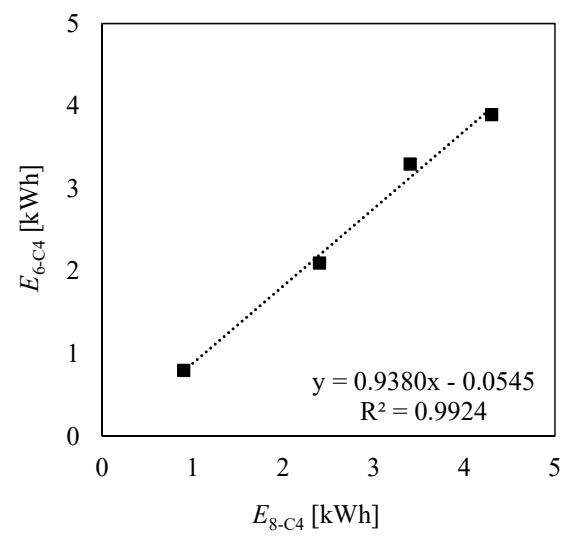

(b)

Figure 9. Regressed function between daily electricity consumption of (a) 6-C3 and 8-C3 and (b) 6-C4 and 8-C4 at the baseline stage.

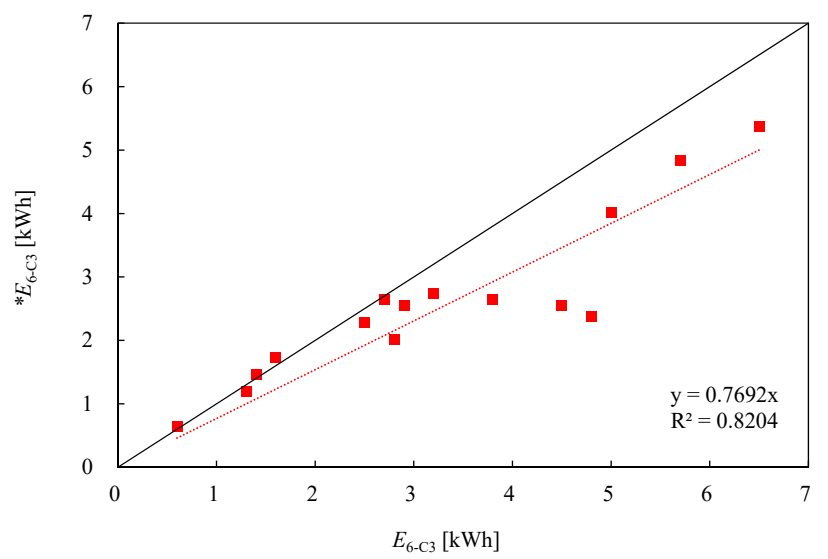

(a)

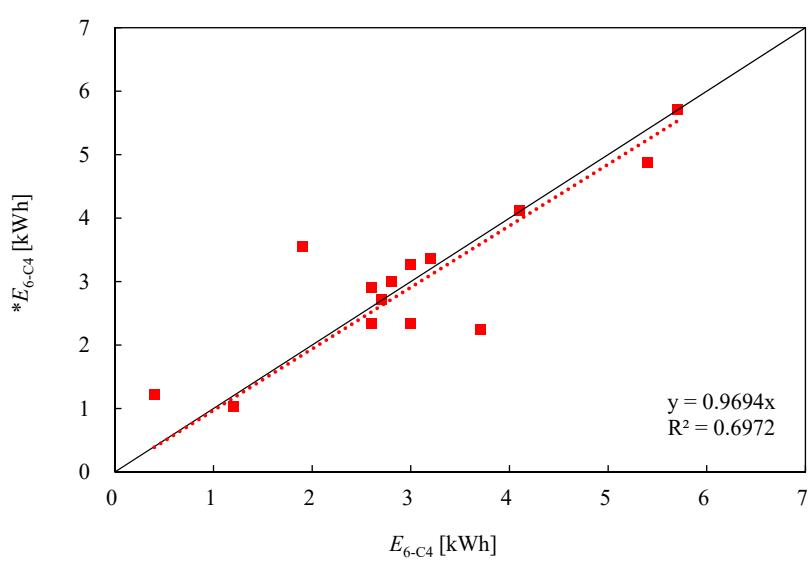

(b)

Figure 10. Corrected electricity consumption $\left({ }^{*} E\right)$ versus actual consumption $(E)$ for (a) 6-C3 and (b) 6-C4. 
Intriguingly, the energy consumption changes are different when the modification scheme is implemented in rooms with different orientations. In fact, the analysis described in Section 3.3.1 and Section 3.3.2 has shown that the air conditioning load in room C4 is dominated by solar radiation heat, whereas room C3 is dominated by the heat transfer between indoor and outdoor temperatures. The core of the upgrade scheme is to enhance the ability of the envelope structure to block the solar radiation while appropriately reducing the requirements for the heat transfer coefficient of the wall. Naturally, the scheme is more suitable for rooms suffered from western exposure, but it should be noted that the airconditioning cooling load of rooms such as C3 may not increase significantly throughout the year. Because the temperature in Panzhihua is in fact low during most of the summer nights, internal insulation will hinder the heat emission from the room to the outside at nighttime, which will increase the load throughout the day. Previous studies have also pointed out that in areas where summer cooling is the main demand, buildings are prone to an "over-insulation," particularly in rooms with severe western sun exposure [23].

\section{Discussion}

The aim of this study is to provide a building energy-saving design modification method which emphasizes updated and precise local climate data as well as residents' living habits. The method suggests that insulation of residential buildings in hot summer and warm winter zone should be removed. The improved building envelope can ensure thermal comfort at much lower cost. This conclusion plays an important role in promoting building energy conservation in cost-sensitive regions like Panzhihua. According to the requirements of the conventional building energy-saving design scheme, both public and residential buildings in Panzhihua are equipped with thermal insulation. The insulation not only occupies the indoor space, but more importantly, there is almost no heating demand in the local area. Residents usually remove the insulation layer spontaneously after moving in, causing a large waste of funds. According to statistics, since 2015, the annual capital loss caused by the construction and removal of external wall insulation in Panzhihua area has been approximately 177 million RMB, and the total capital loss has been approximately 885 million RMB. In fact, the Panzhihua area is rich in solar resources, and the savings from the removal of the insulation measures proposed in this paper can support the procurement and installation of solar water heaters for 300,000 households. The use of renewable energy can also compensate for some of the increase in building energy consumption.

There are still certain limitations to the current study. First, because the removal of the external wall insulation directly affects the ability of the building to withstand the cold, it is necessary to further verify the changes in thermal comfort and building energy consumption during winter to objectively and comprehensively assess the feasibility of the upgrade scheme. In addition, the residential project for the experiments has yet to be delivered, which makes it very different from the actual rooms. For example, the actual room has internal thermal interference from occupants, lighting, and other indoor equipment, as well as the impact of ventilation on the indoor environment from people opening windows. A further study will be carried out progressively as winter approaches and the project is delivered.

\section{Conclusions}

This study proposes a method of modifying building energy-saving design based on research into the local climate and residents' living habits, and a residential building in Panzhihua was selected for trial. The following results were obtained:

(1) According to the research, an economical building energy-saving design scheme for hot summer and warm winter zone is proposed to strengthen the shading and window insulation design, while relatively weaken the insulation of walls.

(2) The field test results show that the upgraded scheme leads to trivial increase in indoor $\mathrm{SET}^{*}$ during the summer and can meet the thermal comfort requirements. 
(3) For rooms exposed to strong solar radiation, the upgraded scheme brought about $11 \%$ decrease in energy consumption, while for rooms that are mainly influenced by outdoor air temperature, the energy consumption increased by approximately $20.7 \%$ during the test period.

(4) Since Panzhihua is rich in solar energy resources, the increased energy consumption can be compensated by the use of solar energy, and the savings from the cancellation of the external envelope insulation can be used to support the purchase and installation of solar water heaters for the residents.

In conclusion, rigid compliance with prescriptive building energy-saving design codes usually results in an unsatisfactory effect and a waste of funds. The research-based modification method proposed in this study can be used to promote building energy efficiency improvement adapted to local conditions.

Author Contributions: Conceptualization, formal analysis, writing-review \& editing, X.Z.; methodology, data curation, investigation, B.G.; supervision, X.Y.; project administration, Z.Y.; funding acquisition, J.N. All authors have read and agreed to the published version of the manuscript.

Funding: This research was funded by the Key Research and Development Projects of Sichuan Science and Technology Plan, grant number 2020YFS0059.

Institutional Review Board Statement: Not applicable.

Informed Consent Statement: Not applicable.

Data Availability Statement: The data presented in this study are available on request from the corresponding author.

Acknowledgments: The work was supported by the Key Research and Development Projects of Sichuan Science and Technology Plan (grant number 2020YFS0059), the National Natural Science Foundation of China (Grant No. 51838007), and the Innovative Research Groups of the National Natural Science Foundation of China (Grant No. 51521005).

Conflicts of Interest: The authors declare no conflict of interest.

\section{References}

1. Deng, M.; Luo, W.; Yin, L. A systematic review of international theory, research and practice on carbon neutrality. Resour. Sci. 2013, 35, 1084-1094.

2. Bouscayrol, A.; Chevallier, L.; Cimetiere, X.; Clenet, S.; Lemaire-Semail, B. EPE'13 ECCE Europe, a carbon-neutral conference. EPE J. 2018, 28, 43-48. [CrossRef]

3. Lombard, L.P.; Jose, O.; Christine, P. A review on buildings energy consumption information. Energy Build. 2008, 40, $394-398$. [CrossRef]

4. Omar, M.A.; Mohammed, M.A. A survey of energy-efficient strategies for effective air-conditioning. Energy Convers. Manag. 2004, $45,1643-1654$.

5. Yang, L.; Lam, J.C.; Tsang, C.L. Energy performance of building envelopes in different climate zones in China. Appl. Energy 2008, 85, 800-817. [CrossRef]

6. Ma, Z.; Cooper, P.; Daly, D.; Ledo, L. Existing building retrofits: Methodology and state-of-the-art. Energy Build. 2012, 55, 889-902. [CrossRef]

7. DECC. Warmer Homes, Greener Homes: A Strategy for Household Energy Management. UK Department of Energy and Climate Change. Available online: http:/ / www.decc.gov.uk/ (accessed on 10 January 2012).

8. Li, Y.; Kubicki, S.; Guerriero, A.; Rezgui, Y. Review of building energy performance certification schemes towards future improvement. Renew. Sustain. Energy Rev. 2019, 113, 109-244. [CrossRef]

9. Fantozzi, F.; Leccese, F.; Salvadori, G.; Tuoni, G. Energy demand analysis and energy labelling of new residential buildings in Tuscany (Italy). WIT Trans. Ecol. Environ. 2009, 122, 217-229.

10. Asensio, O.I.; Delmas, M.A. The effectiveness of US energy efficiency building labels. Nat. Energy 2017, 2, 17033. [CrossRef]

11. Fantozzi, F; Gargari, C.; Rovai, M.; Salvadori, G. Energy upgrading of residential building stock: Use of life cycle cost analysis to assess interventions on social housing in Italy. Sustainability 2019, 11, 1452. [CrossRef]

12. NBS. China Statistical Yearbook 2016; China Statistics Press: Beijing, China, 2016.

13. Jiang, Y. Current building energy consumption in China and effective energy efficiency measures. Heat. Vent. Air Cond. 2005, 35, 30-40. 
14. Zou, Y.; Lang, S.; Xu, W. Development and prospects for China's building energy efficiency standards. Build. Sci. 2016, 32, 1-5. (In Chinese)

15. GB 50176-2016. Code for Thermal Design of Civil Building; Ministry of Housing and Urban Rural Development of the People's Republic of China: Beijing, China, 2016. (In Chinese)

16. GB 50189-2015. Design Standard for Energy Efficiency of Public Buildings; Ministry of Housing and Urban Rural Development of the People's Republic of China: Beijing, China, 2015. (In Chinese)

17. GB 5011-2019. Standard for Acceptance of Energy Efficient Building Construction; Ministry of Housing and Urban Rural Development of the People's Republic of China: Beijing, China, 2019. (In Chinese)

18. JGJ 176-2009. Technical Code for the Retrofitting of Public Building on Energy Efficiency; Ministry of Housing and Urban Rural Development of the People's Republic of China: Beijing, China, 2009. (In Chinese)

19. JGJ/T 129-2012. Technical Specification for Energy Efficiency Retrofitting of Existing Residential Buildings; Ministry of Housing and Urban Rural Development of the People's Republic of China: Beijing, China, 2012. (In Chinese)

20. Hee, W.J.; Alghoul, M.A.; Bakhtyar, B.; Elayeb, O.; Shameri, M.A.; Alrubaih, M.S.; Sopian, K. The role of window glazing on daylighting and energy saving in buildings. Renew. Sustain. Energy Rev. 2015, 42, 323-343. [CrossRef]

21. Westphal, F.S.; Yamakawa, M.A.; Castro, L.T.D. Thermal insulation of building envelope toward zero energy design in hot-humid climate. In Proceedings of the 12th Conference of International Building Performance Simulation Association, Sydney, Australia, 14-16 November 2011; pp. 2378-2384.

22. Melo, A.P.; Lamberts, R. Envelope Insulation and Heat Balance in Commercial Buildings; International Building Performance Simulation Association: Glassgow, UK, 2009; pp. 2243-2250.

23. Lee, J.; Kim, J.; Song, D.; Kim, J.; Jang, C. Impact of external insulation and internal thermal density upon energy consumption of buildings in a temperate climate with four distinct seasons. Renew. Sustain. Energy Rev. 2017, 75, 1081-1088. [CrossRef]

24. Beller, D. Qualitative versus quantitative aspects of performance-based regulations. In Proceedings of the CIB-CTBUH International Conference on Tall Building, Kuala Lumpur, Malaysia, 20-23 October 2003.

25. Meacham, B.; Bowen, R.; Traw, J.; Moore, A. Performance-based building regulation: Current situation and future needs. Build. Res. Inf. 2005, 33, 91-106. [CrossRef]

26. Sexton, M.; Barrett, P. Performance-based building and innovation: Balancing client and industry needs. Build. Res. Inf. 2005, 33, 142-148. [CrossRef]

27. Felius, L.C.; Dessen, F.; Hrynyszyn, B.D. Retrofitting towards energy-efficient homes in European cold climates: A review. Energy Effic. 2020, 13, 101-125. [CrossRef]

28. Kalamees, T.; Kuusk, K.; Arumägi, E.; Alev, Ü. Cost-Effective Energy and Indoor Climate Renovation of Estonian Residential Buildings. In Cost-Effective Energy Efficient Building Retrofitting; Woodhead Publishing: Cambridge, UK, 2017 ; pp. 405-454.

29. Liu, L.; Moshfegh, B.; Akander, J.; Cehlin, M. Comprehensive investigation on energy retrofits in eleven multi-family buildings in Sweden. Energy Build. 2014, 84, 704-715. [CrossRef]

30. Zangheri, P.; Armani, R.; Pietrobon, M.; Pagliano, L. Identification of cost-optimal and NZEB refurbishment levels for representative climates and building typologies across Europe. Energy Effic. 2018, 11, 337-369. [CrossRef]

31. Gagge, A.P.; Fobelets, A.P.; Bergland, L.G. A standard predictive index of human response to the thermal environment. ASHRAE Trans. 1986, 92, 709-731.

32. ASHRAE. Thermal Environmental Conditions for Human Occupancy, ASHRAE Standard 55-2017; American Society of Heating, Refrigerating and Air-conditioning Engineers: Atlanta, GA, USA, 2017.

33. Du, H.; Yang, C. Re-visitation of the thermal environment evaluation index standard effective temperature (SET ${ }^{*}$ ) based on the two-node model. Sustain. Cities Soc. 2020, 53, 101899. [CrossRef]

34. O'Donovan, A.; O'sullivan P., D.; Murphy, M.D. A field study of thermal comfort performance for a slotted louvre ventilation system in a low energy retrofit. Energy Build. 2017, 135, 312-323. [CrossRef]

35. Enescu, D. A review of thermal comfort models and indicators for indoor environments. Renew. Sustain. Energy Rev. 2017, 79, 1353-1379. [CrossRef]

36. Bojić, M.; Yik, F.; Sat, P. Energy performance of windows in high-rise residential buildings in Hong Kong. Energy Build. 2002, 34, 71-82. [CrossRef]

37. Rijal, H.B.; Humphreys, M.A.; Nicol, J.F. Development of a window opening algorithm based on adaptive thermal comfort to predict occupant behavior in Japanese dwellings. Jpn. Archit. Rev. 2018, 1, 310-321. [CrossRef]

38. Rijal, H.B.; Humphreys, M.A.; Nicol, J.F. Adaptive model and the adaptive mechanisms for thermal comfort in Japanese dwellings. Energy Build. 2019, 202, 109371.1-109371.14. [CrossRef]

39. Krause, P.; Nowowiat, A. Experimental studies involving the impact of solar radiation on the properties of expanded graphite polystyrene. Energies 2019, 13, 75. [CrossRef]

40. Zirkelbach, D.; Kuenzel, H.M.; Sedlbauer, K. Application of external thermal insulation composite systems under various climate conditions. Bauphysik 2004, 26, 335-339. [CrossRef]

41. Rijal, H.B. Thermal adaptation of buildings and people for energy saving in extreme cold climate of Nepal. Energy Build. 2021, 230, 110551. [CrossRef]

42. Rijal, H.B.; Yoshida, K.; Humphreys, M.A.; Nicol, J.F. Development of an adaptive thermal comfort model for energy-saving building design in Japan. Archit. Sci. Rev. 2020, 1, 1-14. [CrossRef] 